\title{
Prevalence and factors associated with metabolic syndrome among Tamils aged over 18 years in Jaffna district, Sri Lanka
}

\author{
Sivarathy Amarasinghe ${ }^{*}$, Sandrasegarampillai Balakumar and Vasanthy Arasaratnam
}

\begin{abstract}
Background: The aim was to determine the prevalence and factors associated with Metabolic Syndrome (MS) among adults aged over 18 years in Jaffna district, Sri Lanka.

Methods: This study was carried out as a community based cross sectional descriptive study in Jaffna district, Sri Lanka. Multistage stratified cluster sampling technique was employed. Total sample size was 544. An interviewer administrated questionnaire was used to gather data. Waist circumference (WC) and blood pressure (BP) measurements were recorded in standard method. Overnight fasting blood samples were obtained from all subjects. Fasting plasma glucose (FPG), high density lipoprotein (HDL), and triacylglycerols were analyzed by the enzymatic colorimetric assay (Semi Automated analyser Teco Diagnostics TC 3300). Modified National Cholesterol Education Program's Adult Treatment Panel III (NCEP ATP III) criterion was used to define the MS.

Results: Sample response rate was $95.3 \%$. Of them, $43.8 \%(n=224)$ was male. Prevalence of central obesity (WC for male $\geq 102 \mathrm{~cm}$, female $\geq 88 \mathrm{~cm}$ ) was $16.2 \%$. Prevalence of raised FPG $(\geq 100 \mathrm{mg} / \mathrm{dL}$ ), hypertriacylglycerolaemia ( $\geq 150 \mathrm{mg} / \mathrm{dl})$, low level of HDL cholesterol $(<40 \mathrm{mg} / \mathrm{dL}$ in males, $<50 \mathrm{mg} / \mathrm{dL}$ in females) and raised BP (systolic BP $\geq 130$ or diastolic BP $\geq 85 \mathrm{mmHg}$ ) were $23.9,25,79.3$ and $36.6 \%$ respectively. Prevalence of MS was $24.1 \%$ ( $n=123,95 \%$ Cl: 20.4-28) and it was 26.8 and $21.9 \%$ among males and females respectively. Participants living in urban area had higher prevalence of MS when compared with participants living in rural area $(P=0.015)$. Older age $(P<0.001)$ and smoking $(P=0.005)$ were risk factor for development of MS. Prevalence of MS among the participants with sedentary and active lifestyle was 29.9 and $23.7 \%$ respectively.
\end{abstract}

Conclusion: One out of four had MS. Old age, urban living and smoking carried higher risk for developing MS in Jaffna community.

Keywords: Fasting plasma glucose, High density lipoprotein, Hypertriacylglycerolaemia, Metabolic syndrome, Central obesity

\section{Background}

MS is a combination of medical disorders that increase the risk of developing cardiovascular disease (CVD) and diabetes conditions such as raised FPG, abdominal obesity, high triacylglycerol, low high density lipoprotein and high blood pressure [1]. A recent study showed that the prevalence of MS ranged from 35.8 to $45.3 \%$ in India [2] and 30.5 to $31.5 \%$ in China [3]. A study carried out

\footnotetext{
* Correspondence: rathybio@gmail.com

Department of Biochemistry, Faculty of Medicine, University of Jaffna, Jaffna,
} Sri Lanka

\section{Ciomed Central}

in urban Asian Indian adults using modified ATP III criteria, MS was present in $41.1 \%$ [4]. Identifying participants with MS would help to prevent the increasing morbidity and mortality due to type 2 diabetes mellitus and CVD in Jaffna district. The aim of this study was to determine the prevalence and factors associated with MS among adults in Jaffna district, Sri Lanka.

\section{Methods}

This was a community based cross sectional descriptive study among adults (above 18 years). A multistage stratified 
cluster sampling was used to obtain a sample that represents the adult population of the Jaffna district. Total calculated sample size was 544. The first stage of sampling the population in the Jaffna district was stratified into urban and rural sectors. The 32 clusters were allocated by probability proportion of size of the population in each sector. Considering proportion of the population, 7 and 25 clusters were selected from the urban and rural sectors respectively. Seventeen individuals were included in a cluster, so that the required sample size of 544 was scattered in 32 clusters. An updated list of households was available with the Grama Niladari officer. A household was randomly selected from this list in each of the cluster. In the field, the randomly selected house was located and visited as the first house. Next house to be visited was the one closest to the right side of the front door of the first house. This procedure was repeated until the required number of respondents was interviewed in each cluster. In every house visited, all eligible males and females above 18 years were listed in the summary form. The person to be interviewed was selected randomly using lottery method. This ensured the sex ratio of the study population.

Ethical clearance was obtained from the Ethical Review Committee, Faculty of Medicine, University of Jaffna. Written consent was obtained from individual participants.

Overnight fasting blood samples were obtained from all participants by experienced nurse. The relevant information such as demographic factors, socio- economic factors, family history, and other to ascertain risk factors and medical information was collected using an interviewer administrated questionnaire.

Age was categorized as $18-34,35-49,50-64$ and $\geq 65$ years. Physical activity level was classified into three categories viz. insufficiently active (no activity is reported /some activity is reported but not enough to meet categories of sufficiently active or highly active), sufficiently active ( $\geq 600$ Metabolic Equivalent of Task (MET)-minutes/week) and highly active ( $\geq 3000$ MET-minutes/ week) using the International physical activity questionnaire, which was translated into Tamil and pretested in the preliminary study.

Anthropometric measurements and blood pressure were measured in all participants by trained doctors. Body weight was measured with light cloths without shoes to the nearest $100 \mathrm{~g}$ using an electronic digital weighing scale. Height was measured using a stadiometer without shoes with the participant looking straight ahead. Waist circumference (WC) was taken by positioning the non elastic measuring tape midway between the lower rib margin and the iliac crest, at the end of a normal expiration. Hip circumference (HC) was taken with non elastic measuring tape as maximal circumstances at the buttocks. Blood pressure was measured in the seated position after the participants had rested for at least $5 \mathrm{~min}$. The measurement was taken using the supported left arm at the heart level, using sphygmomanometer. Two recordings were taken and the mean was used for analysis. In the event of variation of over $20 \mathrm{mmHg}$ between recordings, a third reading was done and the mean of the last two recordings was used.

FPG, HDL cholesterol, and triacylglycerols were analyzed by the enzymatic colorimetric assay (Semi Automated analyser Teco Diagnostics TC 3300). Data entry and statistical analysis were done using the SPSS Version 16 statistical package. The probability level was set as $P<0.05$. Multivariable analysis, bivariate correlation and linear regression were used for analysis.

According to modified NCEP ATP III criteria, MS has five components such as central obesity, raised FPG, hypertriacylglycerolaemia, low HDL cholesterol level and raised $\mathrm{BP}$ [2]. If the participants possess any of the mentioned three abnormal parameters, they were identified as they are having MS.

\section{Results}

Sample response rate was $95.3 \%$. Of them, $43.8 \%(n=$ 224) was male. Prevalence of central obesity was $16.2 \%$ according to modified NCEP ATP III criteria. Prevalence of raised FPG $(\geq 100 \mathrm{mg} / \mathrm{dL}$ ), hypertriacylglycerolemia $(\geq 150 \mathrm{mg} / \mathrm{dl})$, low level of HDL cholesterol $(<40 \mathrm{mg} /$ $\mathrm{dL}$ in males, $<50 \mathrm{mg} / \mathrm{dL}$ in females) and raised $\mathrm{BP}$ (systolic BP $\geq 130$ or diastolic BP $\geq 85 \mathrm{mmHg}$ ) were 23.9, 25, 79.3 and $36.6 \%$ respectively (Table 1 ).

Prevalence of MS was $24.1 \%$ ( $\mathrm{n}=123,95 \%$ CI: 20.4-28) and it was $26.8 \%$ (95\% CI: 21.1-33.1) among males and 21.9 \% (95 \% CI: 17.3-27.2) among females. Average values of anthropometric indicators, selected biochemical parameters and blood pressure of participants with metabolic syndrome were significantly higher when compared with participants without metabolic syndrome $(P<0.05$; Table 2).

In the study population, gender was not significantly associated with MS $(P=0.212)$ (Table 3$)$. Total participants were classified based on rural or urban living. In this study, 394 participants $(77.1 \%)$ were from the rural sector and the rest were from the urban sector. In rural area, $21.6 \%(n=85)$ of the participants had MS while $32.5 \%(n=38)$ of the participants had MS in urban area. Participants living in urban area had higher prevalence of MS when compared with participants living in rural area $(P=0.015)$. Females living in urban area had higher prevalence of MS than that of females in rural area (32.2 vs $19.3 \%)$. Similar observation was also made among males (32.8 vs $24.7 \%$ ) (Table 3). Mean age of the participants with MS [54.1 $( \pm 12.2)$ years] 
Table 1 Components of metabolic syndrome (MS) in the study population stratified by gender

\begin{tabular}{|c|c|c|c|c|c|c|c|c|}
\hline \multirow[t]{2}{*}{ Components of MS } & \multirow[t]{2}{*}{ Reference values } & \multicolumn{2}{|l|}{ Male } & \multicolumn{2}{|c|}{ Female } & \multicolumn{2}{|l|}{ Total } & \multirow[t]{2}{*}{$P$ value } \\
\hline & & (No) & $(\%)$ & (No) & $(\%)$ & (No) & $(\%)$ & \\
\hline Central obesity & $W C \geq 102 \mathrm{~cm}$ in males, $\geq 88 \mathrm{~cm}$ in females & 28 & 12.5 & 55 & 19.2 & 83 & 16.2 & $0.000^{a}$ \\
\hline Raised glucose level & FPG $\geq 100 \mathrm{mg} / \mathrm{dL}$ or previously disdiagnosed type 2 diabetes & 60 & 26.8 & 62 & 21.6 & 122 & 23.9 & 0.176 \\
\hline Raised triacylglycerol level & TAG > $150 \mathrm{mg} / \mathrm{dL}$ or specific treatment of lipid abnormality & 63 & 28.1 & 65 & 22.6 & 128 & 25.0 & 0.181 \\
\hline $\begin{array}{l}\text { Low high density lipoprotein } \\
\text { level }\end{array}$ & $\mathrm{HDL}<40 \mathrm{mg} / \mathrm{dL}$ in males, $<50 \mathrm{mg} / \mathrm{dL}$ in females & 181 & 80.8 & 224 & 78 & 405 & 79.3 & 0.51 \\
\hline Raised blood pressure & $\begin{array}{l}\text { Systolic } \mathrm{BP} \geq 130 \text { or Diastolic } \mathrm{BP} \geq 85 \mathrm{mmHg} \text { or previously diagnosed } \\
\text { hypertension }\end{array}$ & 101 & 45.1 & 86 & 30.0 & 187 & 36.6 & $0.001^{a}$ \\
\hline
\end{tabular}

Modified NCEP ATP III (2004) was used to identify the components of metabolic syndrome

${ }^{a}$ significance difference in components of metabolic syndrome between male and female participants

was significantly higher when compared to the mean age of participants without MS $[42.9( \pm 14.0)$ years, $P$ $<0.001]$. Among the age groups of 18-34, 35-49, 5064 and above 65 years prevalence of MS was 9.0, 14.8, 36.6 and $50.9 \%$ respectively. Same observation was done in both males and females. In the study population, old age was a risk for developing MS $(P<0.001)$ (Table 3).

High prevalence of MS was found among professionals $(41.7 \%)$. Monthly household income was categorised as less than LKR 9000, LKR 14,000-19,999, LKR 20,000-31,999, and more than LKR 32,000. Prevalence of MS was calculated to each category. High prevalence of MS was found among subjects who received more than LKR 32,000 as monthly household income (33.3\%).

Among the smokers and the non smokers prevalence of MS was $36.8 \%$ (95 \% CI: 24.4-50.6) and $22.5 \%$ (95\% CI: 18.7-26.6) respectively. Smoking was a risk factor

Table 2 Mean values of anthropometric indicators and selected biochemical parameters of participants with and without metabolic syndrome

\begin{tabular}{|c|c|c|c|}
\hline \multirow[t]{2}{*}{ Variables } & \multicolumn{2}{|l|}{ Mean } & \multirow[b]{2}{*}{$P$ value } \\
\hline & Participants with MS & Participants without MS & \\
\hline Weight (kg) & $61.7 \pm 13.2$ & $55.0 \pm 11.4$ & $0.000^{\mathrm{a}}$ \\
\hline BMI $\left(\mathrm{kg} / \mathrm{m}^{2}\right)$ & $24.9 \pm 4.7$ & $22.5 \pm 4.0$ & $0.000^{\mathrm{a}}$ \\
\hline WC (cm) & $89.6 \pm 12.3$ & $79.4 \pm 11.9$ & $0.000^{\mathrm{a}}$ \\
\hline $\mathrm{HC}(\mathrm{cm})$ & $95.2 \pm 14.3$ & $88.9 \pm 14.5$ & $0.000^{\mathrm{a}}$ \\
\hline WHR & $0.9 \pm 0.1$ & $0.9 \pm 0.1$ & $0.000^{a}$ \\
\hline $\mathrm{SBP}(\mathrm{mm} \mathrm{Hg})$ & $129 \pm 18$ & $115 \pm 16$ & $0.000^{a}$ \\
\hline $\mathrm{DBP}(\mathrm{mm} \mathrm{Hg})$ & $83 \pm 10$ & $75 \pm 11$ & $0.000^{\mathrm{a}}$ \\
\hline FPG (mg/dL) & $126.2 \pm 53.2$ & $83.8 \pm 24$ & $0.000^{\mathrm{a}}$ \\
\hline $\mathrm{HDL}(\mathrm{mg} / \mathrm{dL})$ & $32.8 \pm 8.8$ & $35.0 \pm 9.9$ & $0.025^{\mathrm{a}}$ \\
\hline TAGs (mg/dL) & $164 \pm 38.3$ & $92.6 \pm 34.1$ & $0.000^{\mathrm{a}}$ \\
\hline
\end{tabular}

for development of MS $(P=0.005)$, but type of smoking $(P=0.635)$ and frequency of smoking $(P=0.062)$ were not significantly associated with development of MS. Prevalence of MS was 32.8 \% (95 \% CI: 21.3-46) among the alcohol consumers and $22.9 \%$ (95 \% CI: 19.1-27.1) among the non-alcohol consumers. There was not statistically significant difference in prevalence of MS between alcohol consumers and non-alcohol consumers $(P=0.09)$. Physical activity level was categorized based on international physical activity questionnaire score. Prevalence of MS among the participants with sedentary and active lifestyle was 29.9 \% (95 \% CI: 20.5-40.6) and $23.7 \%$ (95 \% CI: 19.7-28.1) respectively.

\section{Discussion}

In the rest of population in Sri Lanka, crude prevalence of MS was $27.1 \%$ (95 \% CI: 25.8-28.5), and age-adjusted prevalence was $24.3 \%$ (95 \% CI: 23.0-25.6). These values were similar to this finding. In the study population, there was no gender difference $(26.8 \%$ among males, $21.9 \%$ among females). Prevalence in males and females were 18.4 and $28.3 \%$ respectively [5]. In this study, $21.6 \%$ of participants from rural area and $32.5 \%$ of the participants from urban area had MS. Females living in the urban area had higher proportion of MS than those living in rural area (32.2 vs $19.3 \%)$. Similar observation was also made among males (32.8 vs $24.7 \%$; Table 3). Katulanda et al. observed a similar distribution in other regions of the country. MS is more prevalent among urban dwellers in India too [6]. According to the present study, MS was more prevalent to be among the people who are more than 50 years. This is compatible with the findings of the previous study which was done in other parts of Sri Lanka [5]. Older age was significantly contributed to increased risk of MS [7]. With age, adipose deposition could be increased. It may lead to insulin resistance and higher LDL cholesterol, triglycerides, blood glucose, and blood pressure. Geriatric changes in the body systems may invariably contribute to this association. 
Table 3 Prevalence of metabolic syndrome (MS) among the selected participants based on demographic factors

\begin{tabular}{|c|c|c|c|c|c|c|c|c|c|c|c|c|c|}
\hline & \multicolumn{4}{|l|}{ Male } & \multicolumn{4}{|c|}{ Female } & \multicolumn{4}{|l|}{ Total } & \multirow[t]{3}{*}{$P$ value } \\
\hline & \multicolumn{2}{|c|}{ Participants } & \multicolumn{2}{|l|}{ MS } & \multicolumn{2}{|c|}{ Subject } & \multicolumn{2}{|l|}{ MS } & \multicolumn{2}{|c|}{ Participants } & \multicolumn{2}{|l|}{ MS } & \\
\hline & (No) & (\%) & (No) & (\%) & (No) & (\%) & (No) & (\%) & (No) & (\%) & (No) & (\%) & \\
\hline Gender & 224 & 43.8 & 60 & 26.8 & 287 & 56.2 & 63 & 21.9 & 511 & & 123 & 24.1 & 0.212 \\
\hline Sector & & & & & & & & & & & & & $0.019^{a}$ \\
\hline Rural & 166 & 77.1 & 41 & 24.7 & 228 & 79.4 & 44 & 19.3 & 394 & 77.1 & 85 & 21.6 & \\
\hline Urban & 58 & 22.9 & 19 & 32.8 & 59 & 20.6 & 19 & 32.2 & 117 & 22.9 & 38 & 32.5 & \\
\hline Age (Years) & & & & & & & & & & & & & $0.000^{a}$ \\
\hline $18-34$ & 48 & 26 & 5 & 104 & 85 & 29.6 & 7 & 8.2 & 133 & 26 & 12 & 9 & \\
\hline $35-49$ & 69 & 31.7 & 13 & 14.8 & 93 & 32.4 & 11 & 11.8 & 162 & 31.7 & 24 & 14.8 & \\
\hline $50-64$ & 75 & 31.5 & 28 & 36.6 & 86 & 30 & 31 & 36 & 161 & 31.5 & 59 & 36.6 & \\
\hline$>65$ & 32 & 10.8 & 14 & 50.9 & 23 & 8.0 & 14 & 60.9 & 55 & 10.8 & 28 & 50.9 & \\
\hline
\end{tabular}

Modified NCEP ATP III definition of the metabolic syndrome (2004) was used to identify the participants with metabolic syndrome

${ }^{a}$ significance difference in components of metabolic syndrome between male and female participants

High prevalence of MS was found among professionals (41.7\%). Sedentary lifestyle may be a major factor that contributes to MS in the professional category. Among Jaffna population high prevalence of MS was found among the participants who received more than LKR 32,000 as monthly household income (33.3\%). In other areas of the country, high levels of MS was observed in those with the high level of monthly household income [5].

Smoking was a risk factor for development of MS $(P=0.005)$. Several studies in the past have shown that nicotine leads to insulin resistance, has an antiestrogenic effect and increases the level of stress hormones like cortisol $[8,9]$. In a previous study it has shown that risk of metabolic syndrome was stronger for active male smokers (pooled RR 1.34, 95 \% CI: 1.20 1.50) than for former male smokers (pooled RR 1.19, $95 \%$ CI: 1.00-1.42), and greater for heavy smokers (pooled RR 1.42, 95 \% CI: 1.27-1.59) when compared with light smokers (pooled RR 1.10, 95 \% CI: 0.90-1.35) [10]. There was not statistically significant difference in prevalence of MS between alcohol consumers and non-alcohol consumers $(P=0.09)$. Heavy alcohol consumption was associated with an increased risk of the metabolic syndrome by influencing its components [11]. In contrast to present study, in another study, males who never consumed alcohol had the highest prevalence of MS (12.3\%) [5].

Participants with sedentary life style had higher prevalence of MS $29.9 \%$ (95 \% CI: 20.5-40.6) than active (includes both moderately active and active) participants 23.7 \% (95 \% CI: 19.7-28.1). In Sri Lanka, prevalence of MS in the different physical activity categories of the IPAQ were; 'inactive'-38.8 \% (95\% CI 34.5-43.2), 'moderately active'-33.5 \% (95 \% CI 30.9-36.1) and 'active'-21.1 \% (95 \% CI 19.6-22.7) [5]. Sedentary life style compounded with the change in the nutritional pattern in Jaffna population makes them more vulnerable to non-communicable diseases. Regular exercise could increase energy expenditure and achieve weight loss and increase insulin sensitivity. Exercise could reduce blood pressure, increase HDL cholesterol and lower triglycerides levels.

\section{Conclusion}

One out of four adults had MS. Old age, urban living, and smoking carried higher risk for developing MS in Jaffna community.

\section{Competing interests}

The authors declare that they have no competing interests.

\section{Authors' contributions}

All authors designed the study and prepared the final manuscript. All authors read and approved the final manuscript.

\section{Acknowledgements}

This research was supported by the National Research Council (NRC), Sri Lanka, grant no: 13-122. Authors wished to thank NRC for granting the fund.

Received: 21 April 2015 Accepted: 13 July 2015

Published online: 22 July 2015

\section{References}

1. Alberti KG, Zimmet P, Shaw J. Metabolic syndrome-a new world-wide definition. A consensus statement from the International Diabetes Federation. Diabet Med. 2006;23(5):469-80. Review

2. Ravikiran M, Bhansali A, Ravikumar P, Bhansali S, Dutta P, Thakur JS, et al. Prevalence and risk factors of metabolic syndrome among Asian Indians: a community survey. Diabetes Res Clin Pract. 2010;89(2):181-8.

3. Zuo H, Shi Z, Hu X, Wu M, Guo Z, Hussain A. Prevalence of metabolic syndrome and factors associated with its components in Chinese adults. Metabolism. 2009;58(8):1102-8.

4. Ramachandran A, Snehalatha C, Satyavani K, Sivasankari S, Vijay V. Type 2 Diabetes in Asian-Indian Urban Children. Diabetes Care. 2003;26(4):1022-5.

5. Katulanda P, Ranasinghe P, Jayawardana R, Sheriff R, Matthews DR. Metabolic syndrome among Sri Lankan adults: prevalence patterns and correlates. Diabetol Metab Syndr. 2012;4(1):24.

6. Pandit K, Goswami S, Ghosh S, Mukhopadhyay P, Chowdhury S. Metabolic syndrome in South Asians. Indian J Endocrinol Metab. 2012;16(1):44-55. 
7. Prasad DS, Kabir Z, Dash AK, Das BC. Prevalence and risk factors for metabolic syndrome in Asian Indians: A community study from urban Eastern India. J Cardiovasc Dis Res. 2012;3(3):204-11.

8. Cena H, Tesone A, Niniano R, Cerveri I, Roggi C, Turconi G. Prevalence rate of metabolic syndrome in a group of light and heavy smokers. Diabetol Metab Syndr. 2013;5:28.

9. Chiolero A, Faeh D, Paccaud F, Cornu J. Consequences of smoking for body weight, body fat distribution, and insulin resistance. Am J Clin Nutr. 2008:87:801-9.

10. Sun K, Liu J, Ning G. Active smoking and risk of metabolic syndrome: a meta-analysis of prospective studies. PLoS One. 2012;7(10), e47791.

11. Baik I, Shin C. Prospective study of alcohol consumption and metabolic syndrome1'2'3. Am J Clin Nutr. 2008;87(5):1455-63.

\section{Submit your next manuscript to BioMed Central and take full advantage of:}

- Convenient online submission

- Thorough peer review

- No space constraints or color figure charges

- Immediate publication on acceptance

- Inclusion in PubMed, CAS, Scopus and Google Scholar

- Research which is freely available for redistribution 